\title{
Factors Affecting the Outcomes of Coronally Advanced Flap Root Coverage Procedure
}

\author{
Lien-Hui Huang, ${ }^{*}$ Rodrigo E.F. Neiva, ${ }^{\dagger}$ and Hom-Lay Wang ${ }^{\dagger}$
}

Background: The coronally advanced flap (CAF) has been used to treat gingival recession. However, the final outcomes (percentage of root coverage) vary from case to case. Hence, the purpose of this study was to analyze the factors that may affect the results of CAF root coverage procedures.

Methods: Twenty-three systemically healthy patients (mean age, $43.8 \pm 11.9$ years) each with one Miller's Class I buccal recession defect were included. Baseline clinical parameters included recession depth (RD), recession width (RW), gingival thickness (GT), width of keratinized tissue (WKT), clinical attachment level (CAL), probing depth (PD), plaque index (PI), and gingival index (GI). CAF root coverage procedures were performed to correct the recession defects. Patients were followed at 2, 4, 12, and 24 weeks postsurgery, at which time wound healing index (WHI) and other measurements were recorded.

Results: The mean baseline RD was $2.9 \pm 0.4 \mathrm{~mm}$; RW, $3.4 \pm 0.6 \mathrm{~mm}$; WKT, $2.7 \pm 1.3 \mathrm{~mm}$; and GT, $1.1 \pm 0.3 \mathrm{~mm}$. At mid-buccal, the mean CAL was $4.5 \pm 0.8 \mathrm{~mm}$. Six months after surgery, the average RC was $82.3 \% \pm 24.7 \%$; RD, $0.5 \pm$ $0.7 \mathrm{~mm}$; RW, $0.4 \pm 0.9 \mathrm{~mm}$; WKT, $3.2 \pm 0.9 \mathrm{~mm}$; and GT, $1.5 \pm 0.5 \mathrm{~mm}$. At mid-buccal, the mean CAL was $1.8 \pm 1.1$ $\mathrm{mm}$. From baseline to the 6 -month follow-up, the changes of RC, RD, RW, WKT, GT, and CAL showed statistical significance $(P<0.05)$. Fourteen patients achieved $100 \% \mathrm{RC}$. The mean RC in partial coverage cases was $54.8 \% \pm 16.8 \%$. Analysis revealed that an initial GT thicker than $1.2 \pm 0.3 \mathrm{~mm}$ was associated with complete root coverage at the 6 -month follow-up $(P<0.05)$.

Conclusions: CAF is a predictable procedure to treat Miller's Class I mucogingival defects. Initial GT was the most significant factor associated with complete root coverage. J Periodontol 2005; 76:1729-1734.

\section{KEY WORDS}

\section{Gingival recession/surgery; gingival recession/therapy;} outcomes assessment; surgical flaps.

\footnotetext{
* Currently, private practice, Taipei, Taiwan; previously, Department of Periodontics, Prevention, and Geriatrics, University of Michigan School of Dentistry, Ann Arbor, MI $\dagger$ Department of Periodontics, Prevention, and Geriatrics, University of Michigan School of Dentistry.
}

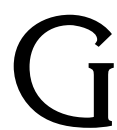
ingival recession causes periodontal attachment loss. If left untreated or unmonitored, it can be detrimental to periodontal or dental health. Therefore, various root coverage procedures have been suggested to correct the recession defects. Among these techniques, the coronally advanced flap (CAF) has been used solely ${ }^{1,2}$ or combined with other procedures, e.g., guided tissue regeneration (GTR)-based root coverage $^{3}$ and subepithelial connective tissue graft. ${ }^{4}$

The effectiveness of CAF has been reviewed. ${ }^{2,5,6}$ The primary clinical outcome is the percentage of coverage of the previously exposed root surface. However, due to diverse study designs and techniques, there is a wide range of results. A well-controlled randomized clinical trial with adequate power is considered the ideal study design that contributes to objective results. Unfortunately, only limited studies are performed in such a manner. Therefore, a metaanalysis, a collection of quality literature according to selected criteria, ranked the study independently, weighted the data correspondingly, and has been accepted as the consensus while discussing the predictability of the procedure. Based on the meta-analyses, ${ }^{5,6}$ for the CAF, the average root coverage ranged from $75 \%$ to $82.7 \%$, with $24 \%$ to $95 \%$ of sites achieving complete root coverage. Conclusions from these articles also confirmed that there were many factors that could influence the outcomes. 
Various studies have examined factors that can be classified as anatomical, patient, and surgical/technical factors. Anatomical factors were adjacent bone height, ${ }^{7}$ adjacent papilla dimension, ${ }^{8}$ defect size, ${ }^{9-14}$ flap thickness, ${ }^{15}$ and the location of the tooth. ${ }^{10} \mathrm{~Pa}$ tient factors, such as smoking, showed negative influences on the clinical results. ${ }^{11,16-18}$ Surgical factors, such as the surgeon's clinical experience, ${ }^{19,20}$ flap tension, ${ }^{21}$ and root surface preparation techniques, ${ }^{2,22-24}$ demonstrated different levels of impact. However, none of the studies investigated the factors that were most associated with successful outcomes. Hence, the purpose of this study was to analyze and identify the factors that affect the outcomes of CAF root coverage procedures.

\section{MATERIALS AND METHODS}

\section{Study Design}

This study was reviewed and approved by the University of Michigan Institutional Review Board committee. Twenty-three patients were recruited from the patient population of the University of Michigan School of Dentistry from January 2, 2003 to February 28,2004 . The inclusion criteria were as follows: 1 ) systemically healthy; 2) non-smokers; 3) patients who were willing to give informed consent; 4) $\geq 18$ years old; 5) ability to maintain good oral hygiene (O'Leary plaque score ${ }^{25} \leq 20 \%$ ); 6 ) maxillary or mandibular incisors, canines, or premolars with Miller's Class I facial mucogingival defects ${ }^{7}$; and 7 ) width of keratinized gingiva $\geq 1 \mathrm{~mm}$. The exclusion criteria were as follows: 1 ) previous mucogingival surgery at the defect; 2) long-term (>2 weeks) use of antibiotics in the past 3 months; 3 ) known allergies to the materials used; 4) with compromised healing potential; 5) with active infectious diseases (hepatitis, tuberculosis, HIV, etc.); 6) taking steroids or medications known to cause gingival enlargement; and 7) pregnant or attempting to get pregnant.

Presurgical treatments included oral hygiene instructions, scaling and root planing, polishing, or occlusal adjustment as indicated. Subjects were required to complete baseline examinations. All surgical procedures were performed by one surgeon. A masked examiner recorded all clinical parameters, i.e., plaque index $(\mathrm{PI})$, gingival index $(\mathrm{GI})$, probing depth (PD), clinical attachment level (CAL), width of keratinized tissue (WKT), recession depth (RD), recession width (RW), and gingival tissue thickness, at baseline and at 3- and 6-month postoperative visits. The wound healing index (WHI) was recorded at 10 to 14 days and 1,3 , and 6 months after the surgery.

\section{Clinical Parameters}

Measuring stents were made from self-curing orthodontic acrylic resin. Clinically reproducible mea- suring points were marked on the stent at the mesio-buccal, mid-buccal, and disto-buccal as standardized reference points.

1. PD was measured from the free gingival margin to the most apical part of the sulcus at mesio-buccal, mid-buccal, disto-buccal points on the stent to the nearest $0.5 \mathrm{~mm}$ with a University of North Carolina (UNC) probe.

2. CAL was measured from the cemento-enamel junction (CEJ) to the most apical part of the sulcus at the same reference points on the stent with the UNC probe.

3. WKT was measured at the mid-buccal point from the mucogingival junction (MGJ) to the free gingival margin by a Boley gauge.

4. RD was measured by a Boley gauge at the midbuccal point. The calculation was the distance from the stent to the most apical point of free gingival margin subtracted from the distance from the stent to CEJ, which remained as a constant for each case throughout the study.

5. RW was measured at $1 \mathrm{~mm}$ apical to the CEJ by a Boley gauge.

6. Gingival thickness (GT) was measured at the mid-buccal $2 \mathrm{~mm}$ apical to the free gingival margin by penetrating a UNC probe into the tissue and recorded to the nearest $0.5 \mathrm{~mm}$.

7. PI was recorded according to Silness and Löe. ${ }^{26}$

8. GI was recorded according to Löe. ${ }^{27}$

9. WHI was recorded after surgery using the following criteria: score $1=$ uneventful healing with no gingival edema, erythema, suppuration, patient discomfort, or flap dehiscence; score 2 = uneventful healing with slight gingival edema, erythema, patient discomfort, or flap dehiscence, but no suppuration; and score 3 = poor wound healing with significant gingival edema, erythema, patient discomfort, flap dehiscence, or any suppuration.

10 . The percentage of root coverage (RC) was calculated as ([RD preoperative - RD postoperative]/RD preoperative) $\times 100 \%$.

\section{Surgical Protocol}

After achieving profound local anesthesia, sulcular incisions were made using $15 \mathrm{C}$ blades on the buccal side. The incisions at the papillae were made following their outline. The distance between the tip of the papillae and the incisions was the recession depth plus $1 \mathrm{~mm}$ or more. Two vertical incisions were made at the line angle of adjacent teeth and extended into the mucosa. A full-thickness flap was elevated. A releasing incision through the periosteum was made to allow the flap to be coronally positioned to cover the defect and CEJ without tension. Deepithelialization was performed at the papilla to provide the connective tissue bed for flap adaptation. The exposed root 
surface was thoroughly planed by periodontal curets, high-speed fine carbide burs, and low-speed fine diamond burs to obtain a smooth and hard surface. After all procedures were finished, the flap was coronally advanced to cover the exposed root and sutured with 5-0 polyglactin $910 .^{\ddagger}$ Gentle pressure was applied to achieve hemostasis and a close adaptation of the flap to the underlying surface. No surgical dressing was used.

Postoperative instructions were provided in oral and written forms. Analgesics (non-steroidal antiinflammatory drugs [NSAIDs]) were prescribed to control postoperative discomfort. No antibiotic was prescribed. Patients were informed not to brush or floss the surgical sites for 3 to 4 weeks. Instead, they were instructed to alternate rinsing with salt water and $0.12 \%$ chlorhexidine gluconate rinse. Sutures were removed 10 to 14 days after the surgery. Oral hygiene instructions and professional cleaning were performed at each follow-up visit when indicated.

\section{Statistical Analysis}

Data were reported as mean \pm standard deviation. A statistical software program was used. $\S$ The Wilcoxon signed rank test was used to analyze parameters before and after treatment. The Mann-Whitney test was performed to evaluate the relationships of the specific factors and prediction of complete root coverage. A restricted/residual maximal likelihood (REML)-based mixed effect model was used for multivariate regression analysis of the factors that may influence the outcomes. All tests were two-sided, and differences were considered statistically significant when $P<0.05$.

\section{RESULTS}

\section{Demographic Results}

Twenty-three patients were treated. The mean age of these patients was $43.8 \pm 11.9$ years (ranging from 24 to 63 years). There were 17 females and six males. Nineteen maxillary (11 canines and eight premolars) and four mandibular (two incisors and two premolars) teeth were treated.

\section{Clinical Parameters}

The average baseline RD was $2.9 \pm 0.4 \mathrm{~mm}$ (range: 2.5 to $4 \mathrm{~mm}$ ); RW, $3.4 \pm 0.6 \mathrm{~mm}$ (range: 2 to 4.2 $\mathrm{mm}$ ); WKT, $2.7 \pm 1.3 \mathrm{~mm}$ (range: 1 to $5.8 \mathrm{~mm}$ ); and GT, $1.1 \pm 0.3 \mathrm{~mm}$ (range: 0.5 to $2 \mathrm{~mm}$ ). At mid-buccal, the mean PD was $1.7 \pm 0.8 \mathrm{~mm}$ (range: 1 to $4 \mathrm{~mm}$ ) and CAL, $4.5 \pm 0.8 \mathrm{~mm}$ (range: 3.5 to $6.5 \mathrm{~mm}$ ). PI and GI ranged between 0 and 2 .

At the 6-month follow-up, the average $\mathrm{RC}$ was $82.3 \% \pm 24.7 \%$ (range: $20 \%$ to $100 \%$ ); RD, $0.5 \pm 0.7$ $\mathrm{mm}$ (range: 0 to $2 \mathrm{~mm}$ ); RW, $0.4 \pm 0.9 \mathrm{~mm}$ (range: 0 to $2.5 \mathrm{~mm}$ ); WKT, $3.2 \pm 0.9 \mathrm{~mm}$ (range: 2 to 6 $\mathrm{mm}$ ); and GT, $1.5 \pm 0.5 \mathrm{~mm}$ (range: 1 to $2.5 \mathrm{~mm}$ ). At mid-buccal, the mean PD was $1.3 \pm 0.6 \mathrm{~mm}$ (range:
1 to $3 \mathrm{~mm}$ ) and CAL, $1.8 \pm 1.1 \mathrm{~mm}$ (range: 0 to $4 \mathrm{~mm}$ ). The mean WHI at the 2 -week follow-up was $1.2 \pm 0.4$. After 1 month, the WHI was 1 for each case. From baseline to the 6-month follow-up, the changes of RC, RD, RW, WKT, GT, and CAL at mid-buccal point showed statistical significance $(P<0.05)$. PI and GI were higher after the surgical procedure; however, they gradually returned to baseline with the resumption of oral hygiene routines.

Factors Associated With Complete Root Coverage After 6 months, there were 14 patients who achieved $100 \%$ RC. The data was stratified into two groups: complete and partial coverage. The average RC in the partial coverage group was $54.8 \% \pm 16.8 \%$ (range: $20 \%$ to $79.3 \%$ ). Analysis was performed based on factors such as patient age, tooth location (maxillary versus mandibular), GT, initial RD, initial RW, and surgeon experience (Table 1 ) and revealed that an initial GT thicker than $1.2 \pm 0.3 \mathrm{~mm}$ was greatly associated with complete root coverage at the 6-month follow-up $(P<0.05)$. The mean initial GT of the partial coverage group was $1.0 \pm 0.3 \mathrm{~mm}$. The surgeon experience, patient age, tooth type, initial $\mathrm{RD}$, and initial RW were not critical factors related to complete root coverage $(P>0.05)$.

\section{Multiple Regression Analysis}

The 6-month post-surgical RD reduction and RC was investigated by multiple regression analysis to explore the impact of specific factors, for example, patient age, tooth location (maxillary versus mandibular), initial GT, initial RD, initial RW, the surgeon experience, and the WHI at the 2-week postoperative follow-up. Overall, the tooth location showed a statistical significant relation to predicting RD reduction (Table 2$)$ and RC (Table 3$)(P<0.05)$. The mandibular teeth decreased the RD reduction by $0.9 \mathrm{~mm}$ and RC by $35.4 \%$. The patient's age presented only a marginally statistically significant relation to $\mathrm{RC}(P>0.05)$. Each 1-year increase in age decreased the RC by $0.7 \%$. Excluding the outlier, RC $20 \%$, the initial GT and WHI at the 2-week follow-up showed a statistically significant relation to RD reduction (Table 4$)$ and RC (Table 5) $(P<0.05)$.

\section{DISCUSSION}

Factors that influenced the final outcomes were analyzed. Initial GT was the most critical factor associated with complete root coverage in the CAF root coverage procedure. Based on this study, if initial GT was $>1.2 \pm$ $0.3 \mathrm{~mm}$, then the chance of achieving $100 \% \mathrm{RC}$ was higher than those GT $<1.2 \mathrm{~mm}$ that were not. This was in agreement with another study that reported

‡ Vicryl, Ethicon, Somerville, NJ. $\S$ SPSS 12, SPSS, Chicago, IL. 
Table I.

Factors Associated With Complete Root Coverage at the 6-Month Follow-Up

\begin{tabular}{lrrcc}
\hline Factors & $\mathrm{RC}(\%)$ & $\mathrm{N}$ & Mean Value* & $P$ Value $^{\dagger}$ \\
\hline Age (years) & 100 & 14 & $41.8 \pm 12.6$ & NS \\
& $<100$ & 9 & $46.9 \pm 10.6$ & \\
Tooth location (maxillary/mandibular) & 100 & 14 & $13 / 1$ & $\mathrm{NS}$ \\
& $<100$ & 9 & $6 / 3$ & \\
Gingival thickness (mm) & 100 & 14 & $1.2 \pm 0.3$ & $0.049 \neq$ \\
& $<100$ & 9 & $1.0 \pm 0.3$ & \\
Initial recession depth (mm) & 100 & 14 & $2.9 \pm 0.4$ & NS \\
Initial recession width & $<100$ & 9 & $2.8 \pm 0.2$ & \\
& 100 & 14 & $3.3 \pm 0.6$ & NS \\
Surgeon experience (days) & $<100$ & 9 & $3.5 \pm 0.6$ & \\
& 100 & 14 & $121.7 \pm 62.8$ & NS \\
\hline
\end{tabular}

* Mean \pm standard deviation.

$\dagger P$ value was based on the Mann-Whitney test.

\# Statistical significance $(P<0.05)$.

$\S$ Surgeon experience was calculated as the days after the first patient was treated.

NS = not statistically significant. that complete root coverage was related to tissue thicker than $0.8 \mathrm{~mm} .{ }^{15}$ The difference of thickness was due to the different measuring techniques. Baldi et al. ${ }^{15}$ measured within the mucosa by an Iwanson gauge. In our study, GT was recorded at $2 \mathrm{~mm}$ apical to the gingival margin by bone sounding using a UNC probe, which measured the keratinized gingiva that would be attached to the exposed root surface after surgery.

Other anatomical factors have been proposed as essential factors to obtain complete root coverage. The level of adjacent periodontal tissue, i.e., interdental papilla ${ }^{8}$ and alveolar bone, ${ }^{7}$ showed direct impact to the final results. Based on the Miller's classification, complete root coverage is more predictable in Class I and II defects than Class
Table 2.

\section{Overall Multiple Regression Analysis for Recession Depth Reduction}

\begin{tabular}{lcccl}
\hline Variable & Coefficient & Standard Error & $t$ & $P$ Value \\
\hline$\beta_{0}$ (constant) & -0.97 & 1.04 & -0.93 & 0.364 \\
$\beta_{1}$ (arch) & -0.88 & 0.33 & -2.67 & $0.015^{*}$ \\
$\beta_{2}$ (RD) & 1.22 & 0.36 & 3.43 & $0.003 *$ \\
\hline
\end{tabular}

The dependent variable was recession depth reduction. The predictor variables were tooth location (arch) and initial recession depth (RD). Model: recession depth reduction $=\beta_{0}+\beta_{1}$ arch $+\beta_{2} \mathrm{RD}+\epsilon\left(P<0.05^{*}\right) . \mathrm{R}^{2}=0.55$. Arch: maxillary $=0 ;$ mandibular $=1$.

* Statistical significance.

Table 3.

\section{Overall Multiple Regression Analysis for Root Coverage at 6-Month Follow-Up}

\begin{tabular}{lcccc}
\hline Variable & Coefficient & Standard Error & $t$ & $P$ Value \\
\hline$\beta_{0}$ (constant) & 119.77 & 16.37 & 7.317 & $0.000^{*}$ \\
$\beta_{1}$ (arch) & -35.43 & 10.94 & -3.24 & $0.004 *$ \\
$\beta_{2}$ (age) & -0.72 & 0.36 & -2.00 & 0.59 \\
\hline
\end{tabular}

The dependent variable was percentage of root coverage. The predictor variables were tooth location (arch) and age. Model: root coverage $=\beta_{0}+\beta_{1}$ arch $+\beta_{2}$ age $+\epsilon\left(P<0.05^{*}\right) \cdot R^{2}=0.41$. Arch: maxillary $=0 ;$ mandibular $=1$.

* Statistical significance.
III or IV, in which cases lost adjacent alveolar bone height. ${ }^{7}$ Also, complete root coverage was significantly more frequent in sites with lower height adjacent papilla. ${ }^{8}$ Wider recession defects were considered more challenged than narrower ones. ${ }^{9} \mathrm{Ac}$ cording to our study, the mean RW was greater in the partial coverage group. However, the difference did not reach statistical significance. On the other hand, the effect of initial RD on the amount of root coverage remains controversial regarding the effect of initial RD. However, this study demonstrated similar initial $\mathrm{RD}$ between the partial and complete covered cases. Some studies found that increased initial RD was associated with decreased complete root coverage or percentage of root coverage. ${ }^{13,14}$ Others observed a greater reduction of $\mathrm{RD}$ in deep recession defects. ${ }^{10-12}$ The location of the tooth was investigated. Although it was not statistically significant, the trend was that maxillary teeth more predictably achieved complete root coverage than mandibular teeth. Among the teeth treated, mandibular premolars were found to be the most challenged (mean RC, 32.2\% \pm $17.3 \%)$. This finding was in agreement with the previous study. ${ }^{10}$

Other factors examined were patient age and surgeon's experience, which were not well documented in the literature. The mean patient age showed no statistically significant difference between groups; however, the mean age was younger in the complete root coverage group. The clinician learning curve did not show any effect on the final outcomes in this study. However, the surgeon's clinical experience may be a potential factor influencing judgments, case 
Table 4.

\section{Multiple Regression Analysis for Recession Depth Reduction (excluding outlier)}

\begin{tabular}{lcccc}
\hline Variable & Coefficient & Standard Error & $t$ & $P$ Value \\
\hline$\beta_{0}$ (constant) & -2.46 & 0.95 & -2.59 & $0.019^{*}$ \\
$\beta_{1}(\mathrm{GT})$ & 0.90 & 0.33 & 2.69 & $0.015^{*}$ \\
$\beta_{2}(\mathrm{WHI})$ & 0.76 & 0.29 & 2.65 & $0.016^{*}$ \\
$\beta_{3}(\mathrm{RD})$ & 1.31 & 0.31 & 4.26 & $0.000^{*}$ \\
\hline
\end{tabular}

The dependent variable was recession depth reduction. The predictor variables were initial gingival thickness (GT), wound healing index at the 2-week follow-up (WHI), and initial recession depth (RD). Model: recession depth reduction $=\beta_{0}+\beta_{1} \mathrm{GT}+\beta_{2} \mathrm{WHI}+\beta_{3} \mathrm{RD}+\epsilon\left(P<0.05^{*}\right) . \mathrm{R}^{2}=0.62$. WHI $2=1 ;$ WHI $1=0$

* Statistical significance.

\section{Table 5.}

\section{Multiple Regression Analysis for Root Coverage at the 6-Month Follow-Up (excluding outlier)}

\begin{tabular}{lcccc}
\hline Variable & Coefficient & Standard Error & $t$ & $P$ Value \\
\hline$\beta_{0}$ (constant) & 45.26 & 14.76 & 3.07 & $0.006^{*}$ \\
$\beta_{\text {। }}(\mathrm{GT})$ & 31.35 & 12.12 & 2.59 & $0.018^{*}$ \\
$\beta_{2}(\mathrm{WHI})$ & 24.96 & 10.30 & 2.42 & $0.025^{*}$ \\
\hline
\end{tabular}

The dependent variable was percentage of root coverage. The predictor variables were initial gingival thickness (GT) and wound healing index at the 2-week follow-up (WHI). Model: root coverage $=\beta_{0}+\beta_{1} \mathrm{GT}+\beta_{2} \mathrm{WHI}+\epsilon$ $\left(P<0.05^{*}\right) . \mathrm{R}^{2}=0.35$. WHI $2=1$; WHI $1=0$

* Statistical significance.

selection, and surgical skills. Comparing various root surface preparation techniques, either mechanical or chemical, showed no impressive clinical benefits in controlled human studies. ${ }^{22,28-31}$ The only factor showing positive impact during the surgery is flap tension. ${ }^{21}$ Based on this particular study, in the CAF root coverage procedure, flap with greater tension resulted in less root coverage, which was avoided in our surgical protocol.

Multiple regression analyses were performed to weigh the influence of specific predictor variables, such as patient age, tooth location, initial GT, initial $\mathrm{RD}$, initial RW, surgeon experience, and the WHI at the 2-week postoperative follow-up. The dependent variable was the reduction of RD and $R C$. The RD reduction was positively correlated to initial RD and maxillary teeth. Excluding the outlier $(\mathrm{RC}=20 \%)$ in the data, the RD reduction was positively correlated to initial RD, initial GT, and WHI at the 2-week operative follow-up. This suggested that mild postoperative complications, e.g., redness or swelling, did not jeopardize the final clinical outcomes. The RC gain was associated with maxillary teeth. After excluding the outlier, the RC gain was associated with initial GT and WHI at the 2-week operative follow-up.

CAF is a predictable procedure to achieve root coverage in Miller's Class I mucogingival defects. However, several factors may contribute to various results. Based on the results of this study, the initial gingival thickness $(\geq 1.2 \pm 0.3 \mathrm{~mm})$ was the most decisive factor regarding the accomplishment of complete root coverage. To predict the percentage of root coverage or recession depth reduction 6 months after treatment, tooth location, initial gingival thickness, and initial recession depth should be taken into consideration. In addition, better outcomes can be expected in defects with thicker gingival tissue and located in the maxillary arch.

\section{ACKNOWLEDGMENTS}

The authors thank Brady West, Center for Statistical Consult and Research, University of Michigan, Ann Arbor, Michigan, for his assistance in the statistical analyses. This study was supported by the University of Michigan Periodontal Graduate Student Research Fund.

\section{REFERENCES}

1. Allen EP, Miller PD Jr. Coronal positioning of existing gingiva: Short term results in the treatment of shallow marginal tissue recession. $J$ Periodontol 1989;60: 316-319.

2. Harris RJ, Harris AW. The coronally positioned pedicle graft with inlaid margins: A predictable method of obtaining root coverage of shallow defects. Int $J$ Periodontics Restorative Dent 1994;14:228-241.

3. Tinti C, Vincenzi G, Cortellini P, Pini Prato G, Clauser C. Guided tissue regeneration in the treatment of human facial recession. A 12-case report. J Periodontol 1992;63:554-560.

4. Langer B, Langer L. Subepithelial connective tissue graft technique for root coverage. J Periodontol 1985; 56:715-720.

5. Greenwell H, Bissada NF, Henderson RD, Dodge JR. The deceptive nature of root coverage results. J Periodontol 2000;71:1327-1337.

6. Wennstrom JL. Mucogingival therapy. Ann Periodontol 1996;1:671-701.

7. Miller PD Jr. A classification of marginal tissue recession. Int J Periodontics Restorative Dent 1985;5: 8-13.

8. Saletta D, Pini Prato G, Pagliaro U, Baldi C, Mauri M, Nieri M. Coronally advanced flap procedure: Is the interdental papilla a prognostic factor for root coverage?. J Periodontol 2001;72:760-766.

9. Sullivan HC, Atkins JH. Free autogenous gingival grafts. 3. Utilization of grafts in the treatment of gingival recession. Periodontics 1968;6:152-160.

10. Trombelli L, Schincaglia GP, Scapoli C, Calura G. Healing response of human buccal gingival recessions treated with expanded polytetrafluoroethylene 
membranes. A retrospective report. $J$ Periodontol 1995;66:14-22.

11. Zucchelli G, Clauser C, De Sanctis M, Calandriello M. Mucogingival versus guided tissue regeneration procedures in the treatment of deep recession type defects. J Periodontol 1998;69:138-145.

12. Zucchelli G, De Sanctis M. Treatment of multiple recession-type defects in patients with esthetic demands. J Periodontol 2000;71:1506-1514.

13. Harris RJ. Connective tissue grafts combined with either double pedicle grafts or coronally positioned pedicle grafts: Results of 266 consecutively treated defects in 200 patients. Int $J$ Periodontics Restorative Dent 2002;22:463-471.

14. Clauser C, Nieri M, Franceschi D, Pagliaro U, PiniPrato G. Evidence-based mucogingival therapy. Part 2: Ordinary and individual patient data meta-analyses of surgical treatment of recession using complete root coverage as the outcome variable. $J$ Periodontol 2003;74:741-756.

15. Baldi C, Pini-Prato G, Pagliaro $U$, et al. Coronally advanced flap procedure for root coverage. Is flap thickness a relevant predictor to achieve root coverage? A 19-case series. J Periodontol 1999;70:10771084.

16. Trombelli L, Scabbia A. Healing response of gingival recession defects following guided tissue regeneration procedures in smokers and non-smokers. J Clin Periodontol 1997;24:529-533.

17. Muller HP, Eger T, Schorb A. Gingival dimensions after root coverage with free connective tissue grafts. J Clin Periodontol 1998;25:424-430.

18. Martins AG, Andia DC, Sallum AW, Sallum EA, Casati MZ, Nociti FH Jr. Smoking may affect root coverage outcome: A prospective clinical study in humans. $J$ Periodontol 2004;75:586-591.

19. Harris RJ. The connective tissue with partial thickness double pedicle graft: The results of 100 consecutivelytreated defects. J Periodontol 1994;65:448-461.

20. Gray JL, Hancock EB. Guided tissue regeneration. Nonabsorbable barriers. Dent Clin North Am 1998; 42:523-541.

21. Pini Prato G, Pagliaro U, Baldi C, et al. Coronally advanced flap procedure for root coverage. Flap with tension versus flap without tension: A randomized controlled clinical study. J Periodontol 2000;71:188201.

22. Pini-Prato G, Baldi C, Pagliaro U, et al. Coronally advanced flap procedure for root coverage. Treatment of root surface: Root planning versus polishing. $J$ Periodontol 1999;70:1064-1076.

23. Miller PD Jr. Root coverage using the free soft tissue autograft following citric acid application. III. A successful and predictable procedure in areas of deepwide recession. Int $J$ Periodontics Restorative Dent 1985;5:14-37.

24. Bouchard P, Nilveus R, Etienne D. Clinical evaluation of tetracycline $\mathrm{HCl}$ conditioning in the treatment of gingival recessions. A comparative study. J Periodontol 1997;68:262-269.

25. O'Leary TJ, Drake RB, Naylor JE. The plaque control record. J Periodontol 1972;43:38.

26. Silness J, Löe H. Periodontal disease in pregnancy. II. Correlation between oral hygiene and periodontal condition. Acta Odontol Scand 1964;22:121-135.

27. Löe $H$. The gingival index, the plaque index and the retention index systems. J Periodontol 1967;38(Suppl.): 610-616.

28. Oles RD, Ibbott CG, Laverty WH. Effects of citric acid treatment on pedicle flap coverage of localized recession. J Periodontol 1985;56:259-261.

29. Caffesse RG, De LaRosa M, Garza M, Munne-Travers A, Mondragon JC, Weltman R. Citric acid demineralization and subepithelial connective tissue grafts. $J$ Periodontol 2000;71:568-572.

30. Ibbott CG, Oles RD, Laverty WH. Effects of citric acid treatment on autogenous free graft coverage of localized recession. J Periodontol 1985;56:662-665.

31. Trombelli L, Scabbia A, Wikesjö UM, Calura G. Fibrin glue application in conjunction with tetracycline root conditioning and coronally positioned flap procedure in the treatment of human gingival recession defects. J Clin Periodontol 1996;23:861-867.

Correspondence: Dr. Hom-Lay Wang, Department of Periodontics, Prevention, and Geriatrics, University of Michigan School of Dentistry, 1011 N. University Ave., Ann Arbor, MI 48109. Fax: 734/936-0374; e-mail: homlay@umich.edu.

Accepted for publication March 7, 2005. 